\title{
PERAMALAN JUMLAH SISWA-SISWI MELALUI PENDEKATAN METODE REGRESI LINEAR
}

\author{
Dimas Aulia Trianggana \\ ${ }^{1}$ Dosen Tetap Program Studi Informatika Fakultas Ilmu Komputer Universitas Dehasen Bengkulu \\ Jl. Meranti Raya No. 32 Kota Bengkulu 38228 Telp. (0736) 22027, 26957 Fax. (0736) 341139) \\ Email.dimasauliat@gmail.com
}

\begin{abstract}
This application can predict data for the next academic year based on data analysis in the previous academic year on the number of new student registrants per department. With the application, it can help schools in managing school quality assurance, in order to attract interest from prospective students to register at schools based on the available majors. Based on the tests that have been done, it can be concluded that the functionality of the application is running properly and the application is able to display forecasting results based on the input trend data.

Keywords: Forecasting, Number of Students, Linear Regression
\end{abstract}

Abstrak- Aplikasi ini dapat meramalkan data untuk tahun pelajaran berikutnya berdasarkan analisa data pada tahun pelajaran sebelumnya terhadap jumlah pendaftar siswa baru per jurusan. Dengan adanya aplikasi dapat membantu pihak sekolah dalam mengelola penjamin mutu sekolah, agar dapat menarik minat dari calon siswa untuk melakukan pendaftaran di Sekolah berdasarkan jurusan yang tersedia. Berdasarkan pengujian yang telah dilakukan, dapat disimpulkan bahwa fungsional dari aplikasi telah berjalan sebagaimana mestinya dan aplikasi mampu menampilkan hasil peramalan berdasarkan data trend yang diinputkan

Kata Kunci : Peramalan, Jumlah Siswa-Siswi, Regresi Linear

\section{PENDAHULUAN}

Teknologi Informasi yang pesat sangat mempengaruhi kemajuan suatu perusahaan, lembaga, organisasi, maupun instansi pemerintahan untuk mendukung pengambilan suatu keputusan. Dengan adanya teknologi informasi dapat mengoptimalkan aktifitasnya dalam mengambil keputusan dengan efektif dan efisien tanpa terkendala oleh waktu yang berlebihan, biaya berlebihan dan birokrasi yang tidak bertanggung jawab. Hal ini telah banyak diterapkan dalam berbagai bidang, salah satunya adalah Bidang Pendidikan.
Setiap tahun ajaran sering kali terjadi peningkatan maupun penurunan dalam hal pendaftaran siswa baru, hal ini dikarenakan kurangnya promosi atau mengenalkan lebih dekat jurusan yang ada di Sekolah. Terkadang beberapa jurusan memiliki jumlah siswa yang sedikit dan ada juga jumlah siswa yang banyak.

Untuk membantu menganalisis data jumlah siswa/i pada tahun berikutnya, maka dibutuhkan data pada jumlah pendaftar siswa/i pada tahun sebelumnya. Dalam penelitian ini menggunakan data 8 tahun terakhir dengan pendekatan metode Regresi Linear.

Dari uraian tersebut di atas, maka peneliti tertarik untuk mengangkat judul "Peramalan Jumlah Siswa-Siswi Melalui Pendekatan Metode Regresi Linear".

\section{TINJAUAN PUSTAKA}

\section{Pengertian Penerapan}

Penerapan adalah bermuara pada aktivitas, aksi, tindakan, atau adanya mekanisme suatu sistem. Penerapan bukan sekedar aktivitas, tetapi suatu kegiatan yang terencana dan untuk mencapai tujuan kegiatan [1]

Penerapan adalah perbuatan menerapkan, sedangkan menurut beberapa ahli, penerapan adalah suatu perbuatan mempraktekkan suatu teori, metode, dan hal lain untuk mencapai 
tujuan tertentu dan untuk suatu kepentingan yang diinginkan oleh suatu kelompok atau golongan yang telah terencana dan tersusun sebelumnya.

\section{Metode Regresi Linear}

Regresi linear sederhana adalah metode statistik yang berfungsi untuk menguji sejauh mana hubungan sebab akibat antar variabel faktor penyebab (X) terhadap variabel akibatnya. Faktor penyebab pada umunya dilambangkan dengan $\mathrm{x}$ atau disebut juga dengan prediktor, sedangkan variabel akibat dilambangkan dengan y atau disebut juga dengan respon [3].

Analisis regresi adalah bersifat asimetri atau dua arah. Teknik regresi membuat prediksi nilai dengan nilai yang ada pada satu variabel (yang disebut variabel independen) pada variabel lain, yang disebut variabel dependen. Dalam hal ini tujuannya bukan bermaksud membuat prediksi yang sempurna. Dengan informasi pada independen bermaksud membuat prediksi nilai variabel dependen dengan error yang sekecil-kecilnya. Proposisi yang digunakan pada analisis regresi yaitu dari variabel independen $\mathrm{X}$ dan variabel dependen $\mathrm{Y}$ dinyatakan dengan regresi $\mathrm{Y}$ pada $\mathrm{X}$.

Dalam regresi, variabel yang diprediksi disebut kriterium dan variabel yang digunakan untuk memprediksi disebut prediktor. Persamaan yang menyatakan hubungan antara variabel kriterium dan variabel prediktor disebut persamaan regresi.

Analisis regresi merupakan metode statistika yang banyak digunakan dalam penelitian. Istilah regresi pertama kali diperkenalkan oleh Sir Francis Galton pada tahun 1986. Secara umum, analisis regresi adalah kajian terhadap hubungan satu variabel yang disebut sebagai variabel yang diterangkan dengan satu atau dua variabel yang menerangkan. Variabel yang diterangkan selanjutnya disebut sebagai variabel respon, sedangkan variabel yang menerangkan biasa disebut variabel beban.

Metode regresi linier tersusun atas dasar pola hubungan data yang relevan dimasa lalu. Pada umunya variabel yang diprediksi seperti persediaan barang, dinyatakan sebagai variabel yang dicari variabel ini dipengaruhi besarnya oleh variabel bebas. Hubungan yang terjadi antara variabel bebas dengan variabel yang dicari merupakan fungsi.

\section{Visual Basic .Net}

Visual Studio adalah IDE (Integrated Development Environment) yang dapat digunakan untuk mengembangkan aplikasiaplikasi Windows. Visual studio dirancang untuk fokus pada produktivitas. Tool ini disebut juga Rapid Application Development Tools (RAD tools) karena dirancang dan dilengkapi untuk meningkatkan produktivitas. Versi baru dari Visual Studio inversi terbaru dibuat lebih sederhana untuk mempermudah pengguna dalam mempelajarinya dan memenuhi kebutuhan para Programmer [1].

Microsoft Visual Studio merupakan sebuah perangkat lunak lengkap (suite) yang dapat digunakan untuk melakukan pengembangan aplikasi, baik itu aplikasi bisnis, aplikasi 
personal, ataupun komponen aplikasinya, dalam bentuk aplikasi console, aplikasi Windows, ataupun aplikasi Web. .NET Framework merupakan model platform yang memudahkan dalam membangun lingkungan aplikasi yang terdistribusi di Internet

\section{Database}

Basis data merupakan gabungan File data yang dibentuk dengan hubungan/relasi yang logis dan dapat diungkapkan dengan catatan serta bersifat independen. Adapun basis data adalah tempat berkumpulnya data yang saling berhubungan dalam suatu wadah (organisasi/perusahaan) bertujuan agar dapat mempermudah dan mempercepat untuk pemanggilan atau pemanfaatan kembali data tersebut [2]

\section{Diagram Alir Data}

Data Flow Diagram (DFD) adalah sebagai alat pembuatan model yang memungkinkan profesional sistem untuk menggambarkan sistem sebagai suatu jaringan proses fungsional yang dihubungkan antara satu dengan yang lain berupa alur data, baik secara manual maupun komputerisasi [2].

Data flow diagram ini adalah suatu Networks yang menggambarkan suatu sistem automat/komputerisasi, kanalisasi, atau gabungan dari keduanya, yang penggambarannya disusun dalam bentuk kumpulan komponen sistem yang saling berhubungan sesuai dengan aturan mainnya. Keuntungan penggunaan DFD adalah memungkinkan untuk menggambarkan sistem dari level yang paling tinggi kemudian menguraikannya menjadi level yang lebih rendah (dekomposisi). Sedangkan kekurangan penggunaan DFD adalah tidak menunjukkan proses pengulangan (looping), proses keputusan, dan proses perhitungan

\section{Entity Relationship Diagram}

Model data dengan diagram hubungan entitas (Entity Relationship Diagram/ER-D) adalah suatu pemodelan berbasis pada persepsi dunia nyata yang mana terdiri dari kumpulan objek dasar yang disebut dengan entitas (entity) dan hubungan Siantar objek-objek tersebut dengan menggunakan perangkat konseptual dalam bentuk diagram. Sebuah entitas adalah objek yang dibedakan dari objek yang lain oleh himpunan dari atribut [2].

\section{METODOLOGI PENELITIAN}

\section{A. Metode Pengumpulan Data}

Metode pengumpulan data yang digunakan dalam penelitian ini, antara lain :

a. Observasi

Observasi dilakukan dengan mengunjungi Sekolah untuk mengetahui jumlah pendaftaran siswa setiap tahun pelajaran dalam kurun waktu 8 tahun pelajaran terakhir

b. Wawancara

Di mana dilakukan wawancara dengan memberikan pertanyaan yang berkaitan dengan masalah yang dibahas

c. Studi Pustaka

Di mana dilakukan pengumpulan data dengan mencari referensi serta sumber pustaka berupa jurnal, artikel, buku-buku yang didapat dari Internet, Perpustakaan.. 


\section{B. Analisis Sistem}

Dalam analisis sistem, dilakukan kajian terhadap data jumlah pendaftaran siswa per Tahun Pelajaran yang diambil selama 8 tahun terakhir untuk mendapatkan hasil prediksi dengan melalui pendekatan Metode Regresi Linear.

\section{Diagram Konteks}

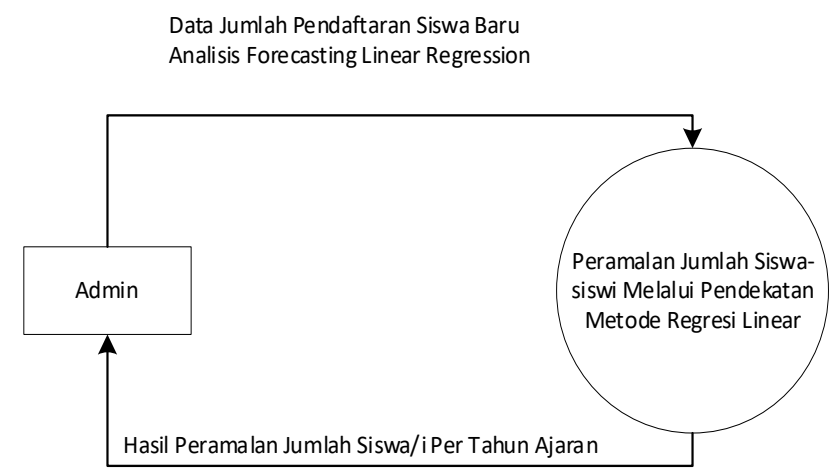

Gambar 1. Diagram Konteks

\section{Diagram Level 0}

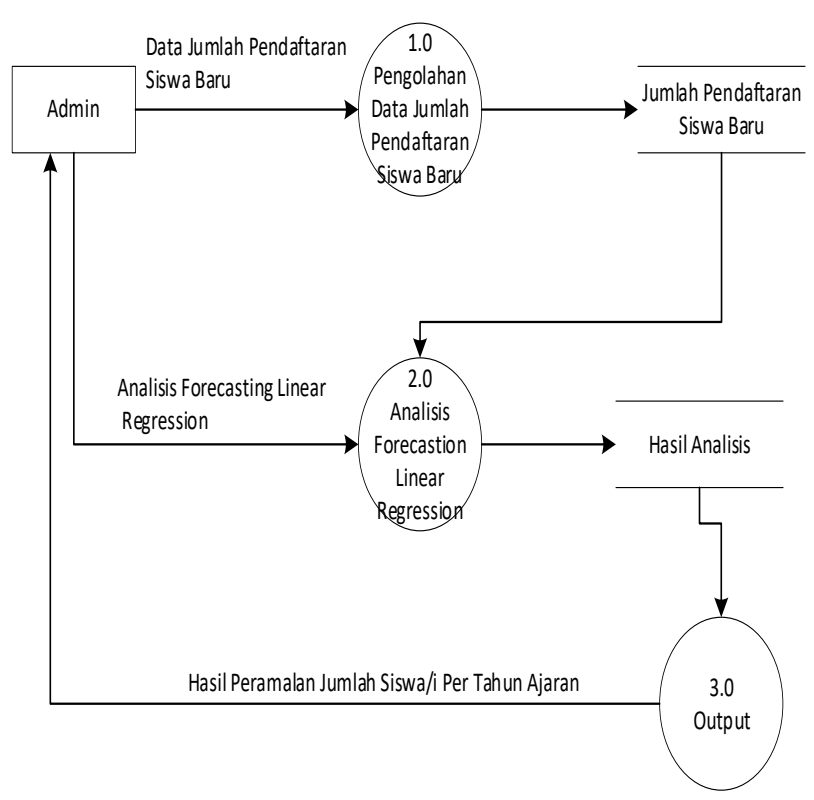

Gambar 2. Diagram Level 0

\section{E. ERD}

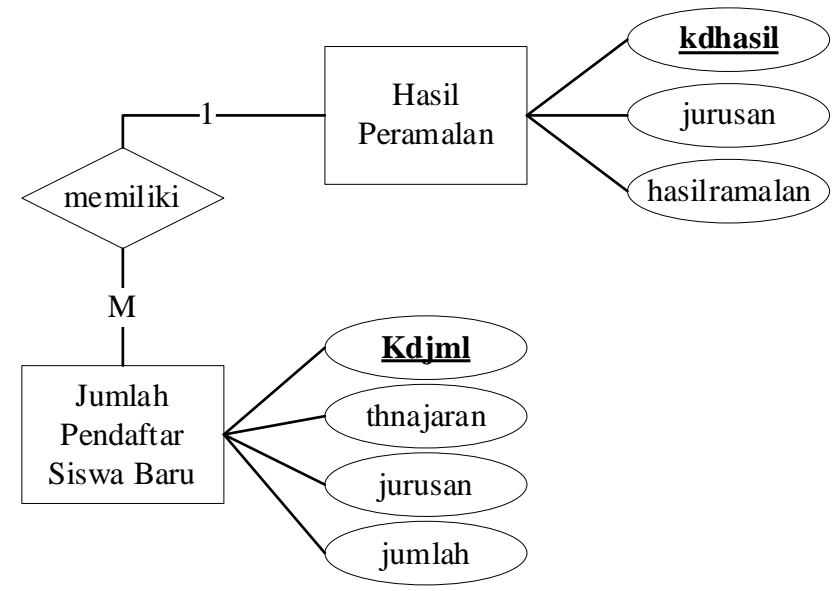

Gambar 3. ERD

\section{HASIL DAN PEMBAHASAN}

Aplikasi peramalan jumlah siswa/i dibuat menggunakan bahasa pemrogramanVB.Net dan database SQL Server dimana pada aplikasi tersebut sudah diimplementasikan metode Regresi Linear. Aplikasi ini dapat meramalkan data untuk tahun pelajaran berikutnya berdasarkan analisa data pada tahun pelajaran sebelumnya terhadap jumlah pendaftaran siswa baru per jurusan.

Dengan adanya aplikasi dapat membantu pihak sekolah dalam mengelola penjamin mutu sekolah, agar dapat menarik minat dari calon siswa untuk melakukan pendaftaran di Sekolah berdasarkan jurusan yang tersedia.

Input data jumlah pendaftaran siswa baru merupakan form input yang digunakan untuk mengolah data jumlah pendaftar siswa baru pada tahun sebelumnya pada aplikasi. Pada form input data jumlah pendaftaran siswa baru dapat dilakukan dengan menambah, mengoreksi, serta menghapus data jumlah pendaftaran siswa baru 


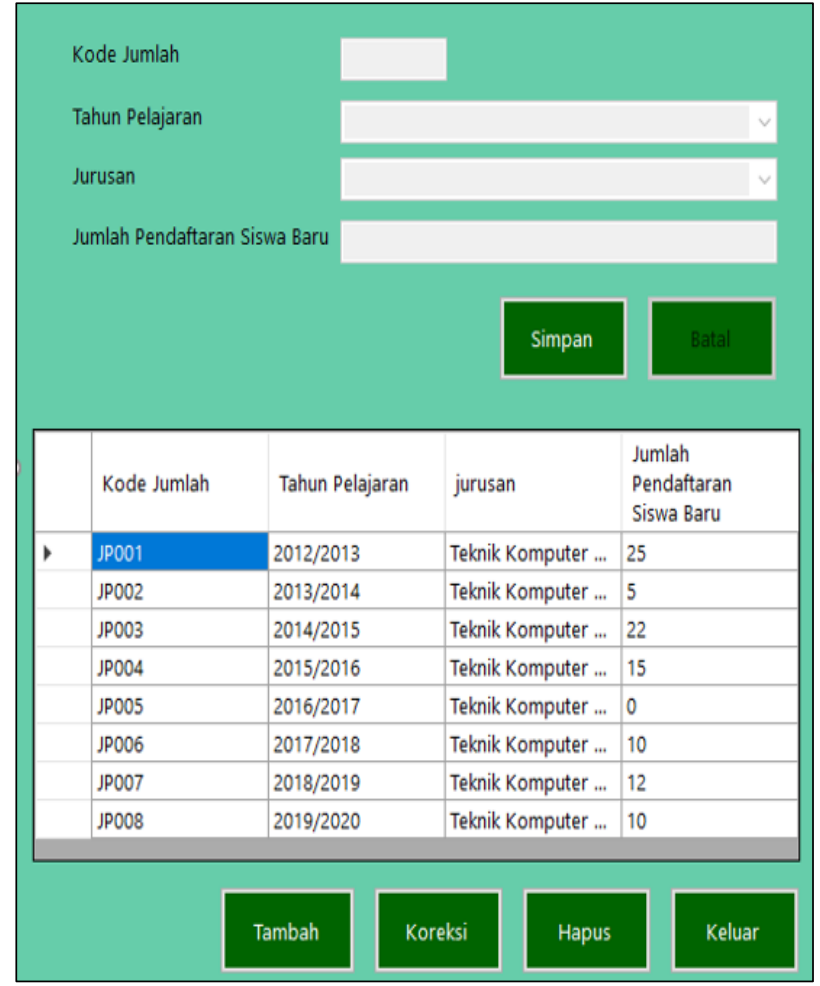

Gambar 4. Input Data Pendaftaran Siswa

\section{Baru}

Analisa Metode Regresi Linear merupakan form yang digunakan untuk menganalisa data jumlah pendaftaran siswa baru agar dapat mengetahui informasi hasil peramalan pada tahun pelajaran berikutnya per jurusan.

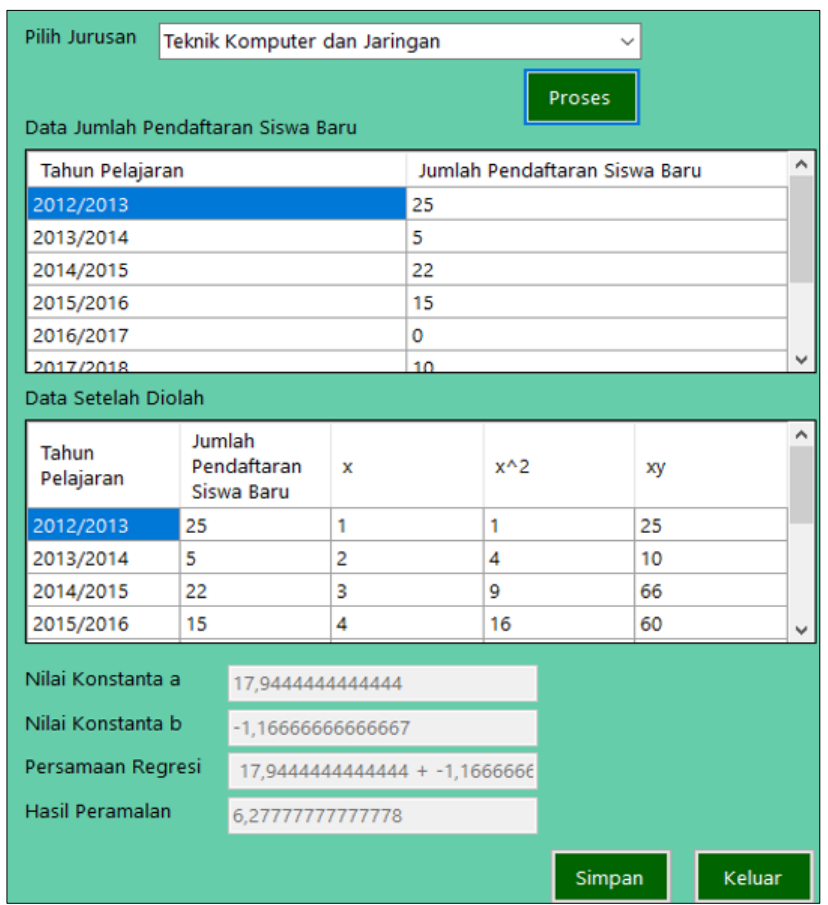

Gambar 5. Analisa
Output hasil dari proses pengolahan data peramalan jumlah pendaftar siswa baru untuk tahun pelajaran berikutnya.

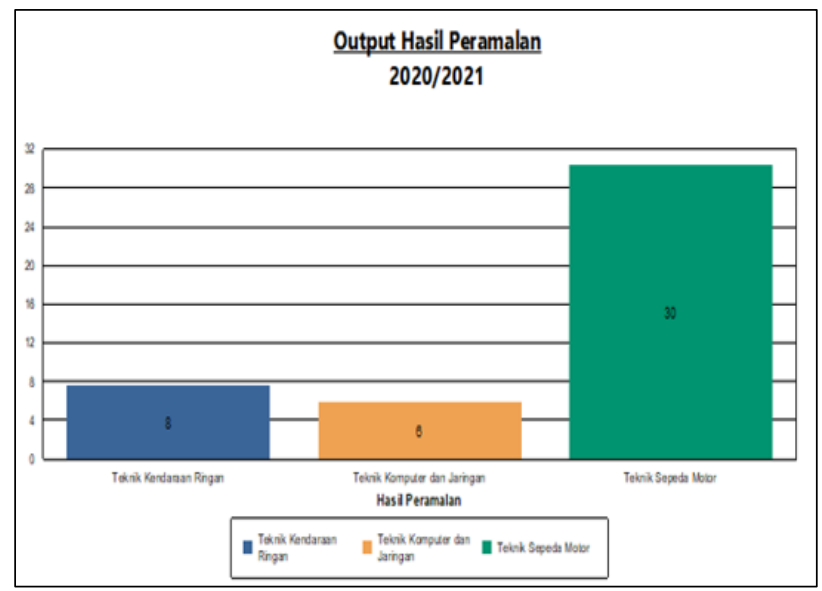

Gambar 10. Output

Berdasarkan pengujian yang telah dilakukan, dapat disimpulkan bahwa :

1) Fungsional dari aplikasi telah berjalan sebagaimana mestinya

2) Aplikasi mampu menampilkan hasil peramalan berdasarkan data trend yang diinputkan.

\section{PENUTUP}

\section{A. Kesimpulan}

Berdasarkan hasil dari pembahasan tersebut, maka dapat disimpulkan bahwa :

1. Aplikasi ini dapat meramalkan data untuk tahun pelajaran berikutnya berdasarkan analisa data pada tahun pelajaran sebelumnya terhadap jumlah pendaftar siswa baru per jurusan.

2. Dengan adanya aplikasi dapat membantu pihak sekolah dalam mengelola penjamin mutu sekolah, agar dapat menarik minat dari calon siswa untuk melakukan pendaftaran di Sekolah berdasarkan jurusan yang tersedia. 
3. Berdasarkan pengujian yang telah dilakukan, dapat disimpulkan bahwa :

a. Fungsional dari aplikasi telah berjalan sebagaimana mestinya

b. Aplikasi mampu menampilkan hasil peramalan berdasarkan data trend yang diinputkan..

\section{B Saran}

Dapat mempergunakan aplikasi ini agar dapat mendapatkan informasi hasil peramalan jumlah pendaftaran siswa baru pada tahun pelajaran berikutnya

\section{DAFTAR PUSTAKA}

[1]Adjis, K. M., 2016. Penerapan 5C Dalam Pembiayaan Murabahah Di BMT Mitra Reksa Bakti. Laporan Universitas Islam Indonesia.

[2]Enterprise, J., 2015. Pengenalan Visual Studio 2013. Jakarta: PT. Elex Media Komputindo..

[3]Herlambang, B. A., 2015. erancangan Data Flow Diagram Sistem Pakar Penentuan Kebutuhan Gizi Bagi Individu Normal Berbasis Web. Jurnal Informatika UPGRIS, Volume 1.

[4]Katemba, P. \& Djoh, R. K., 2017. Prediksi

Tingkat Produksi Kopi Menggunakan Regresi Linear. Jurnal Ilmiah Flash, Volume 3 No.1.

[5]Lubis, A., 2016. Basis Data Dasar Untuk Mahasiswa Ilmu Komputer. Yogyakarta: Deepublish. 